\section{Relevance of stiffness of compression material on venous hemodynamics and edema}

\section{Giovanni Mosti}

Angiology Department, Clinica MD

Barbantini, Lucca, Italy

\section{Abstract}

Elastic and inelastic stockings or bandages may provide the same degree of compression pressure in the resting supine position but inelastic material provides much greater compression pressure in the standing or working position. For elastic compression to have the same effect in the standing or exercising state would require a degree of compression in the resting position that would be intolerable. Studies have shown that this applies to reduction of reflux and improved venous pumping although both appear to have a similar effect for reducing edema.

\section{Introduction}

\section{Stiffness and its importance on venous disease}

Venous reflux, obstruction and reduced venous pumping function from the lower leg during exercise are the main pathophysiological parameters of venous disease. ${ }^{1}$ Compression therapy can improve hemodynamic impairment. In particular compression has been proven effective in reducing venous volume, reflux, venous pumping function, edema and, consequently, ambulatory venous hypertension. ${ }^{2-8}$ Compression may be applied to the leg by different materials: elastic stockings, elastic and inelastic bandages, and/or velcro-banddevices. The main differences between these materials are the exerted pressure and the elastic properties which can influence their hemodynamic effects. The resting pressure produced by a stocking rarely exceeds $40 \mathrm{mmHg}^{9}$ while the resting pressure exerted by a bandage depends mainly on the strength of application. When applied by means of inelastic bandages, which must be applied under full stretch, or of velcro band devices which are completely inelastic and inextensible, the exerted pressure is usually higher than $60 \mathrm{mmHg}$. Nevertheless, the pressure increase when moving from the resting supine to the standing position represents the main difference between elastic and inelastic material, even more important than resting pressure. The pressure increase by standing characterizes the stiffness of the material ${ }^{9}$ and can be measured in vivo ${ }^{10}$ just by subtracting supine from standing pressure. This difference has been termed static stiffness index (SSI) and the cut off in distinguishing elastic from inelastic material is $10 .^{11,12}$ Elastic material gives way to the muscle volume increase during muscle contraction achieving a pressure increase in the standing position only slightly higher than supine resting pressure and always lower than 10 (Figure 1).

Inelastic material doesn't give way to the muscle expansion and the exerted pressure will rise significantly; SSI will always be higher than 10. Other parameters of stiffness are the maximal working pressure, the pressure peaks and pressure amplitudes during walking (the difference between systolic and diastolic pressure). ${ }^{13}$ When inelastic material is correctly applied with full stretch exerting a pressure of $50-60 \mathrm{mmHg}$ in supine position, the significant pressure increase to 70-90 $\mathrm{mmHg}$ with standing will produce a significant vein narrowing or occlusion (Figure 2). Also elastic material could exert this very strong pressure and narrow or occlude the veins but, due to its elastic characteristics, it must be applied with similar strong pressure even at rest which will make the bandage painful and intolerable (Figure 3). ${ }^{14}$ Narrowing/ occlusion of veins by external compression devices is a prerequisite for their hemodynamic efficacy and can be observed with phlebography, Duplex ultrasound or magnetic resonance imaging. The amount of narrowing depends on the body position and the range of compression pressure. In the supine position a pressure of about $20 \mathrm{mmHg}$ is able to narrow the veins while in the upright position, a pressure range of $70-80 \mathrm{mmHg}$ will be necessary to counteract the standing intravenous pressure and to narrow up to near occlusion of the vein lumen. ${ }^{15,16}$ Similar vein narrowing may occur while walking with inelastic materials that produces pressure peaks which overcome the intravenous pressure with every step and leads to an intermittent narrowing of the veins ${ }^{15}$ thus restoring a kind of artificial valve mechanism. ${ }^{17}$ Elastic material or elastic stockings cannot achieve similar results because in order for the compression to be tolerable the exerted pressure range can never exceed $50 \mathrm{mmHg}$. This degree of compression can slightly influence the venous diameter but certainly cannot produce significant vein narrowing. ${ }^{18}$

\section{Relevance of stiffness on reflux and venous pumping function in venous disease}

\section{Effect on reflux}

Reflux has been shown to be abolished both in patients with post-thrombotic syndrome ${ }^{19}$
Correspondence: Giovanni Mosti, Angiology Department, Clinica MD Barbantini, Lucca, Italy. E-mail: jmosti@tin.it

Key words: elastic compression, inelastic compression, venous insufficiency, venous reflux, ejection fraction, edema.

Conference presentation: part of this paper was presented at the International Compression Club (ICC) Meeting on Stiffness of Compression Devices, 2012 May 25, Vienna, Austria (http://www.icc-compressionclub.com/).

Received for publication: 27 October 2012. Revision received: 7 January 2013.

Accepted for publication: 20 February 2013.

This work is licensed under a Creative Commons Attribution 3.0 License (by-nc 3.0).

(C)Copyright G. Mosti, 2013

Licensee PAGEPress, Italy

Veins and Lymphatics 2013; 2:9

doi:10.4081/vl.2013.e9

and severe superficial venous incompetence ${ }^{20}$ by using different methods that produce similar results. In the first study, ${ }^{19}$ the authors used air-plethysmography and were able to show a progressive reduction up to the abolishment of venous reflux by increasing the pressure of compression devices. At every pressure range inelastic material was able to reduce reflux more than elastic material. Only with very strong pressure of $60 \mathrm{mmHg}$ does elastic and inelastic material provide similar result.

In patients with severe reflux of the great saphenous vein ${ }^{20}$ similar results could be demonstrated using Duplex ultrasound: increasing leg compression led to a progressive reduction of reflux, with inelastic always more effective than elastic material.

Reflux reduction up to abolition is due to external pressure which progressively reduces the venous reservoir of the lower leg. The superiority of inelastic compared with elastic material can be explained by higher standing pressure exerted by inelastic material starting from the same supine pressure of 20 or 40 $\mathrm{mmHg}$. This produces a more pronounced narrowing of leg veins, a greater reduction of their reservoir capacity leading to a greater decrease of venous reflux.

A very high pressure will occlude the leg veins irrespective of the elastic properties of materials used; therefore venous reflux is blocked by both elastic and inelastic devices.

Nevertheless it is necessary to take into account that elastic material applied with this strong pressure can be used only for the short period of time of a laboratory test but not in clinical practice because such pressure is barely tolerated by patients. ${ }^{14,20}$ 
In conclusion reflux abolition depends only on the standing pressure necessary to narrow the veins but it is only theoretically independent from the elastic properties of the compression material: elastic material can produce a pressure strong enough to narrow the vein diameter but this pressure will be painful and impossible to use in the clinical practice.

\section{Effect on venous pumping function}

Effects of compression on venous pumping function maybe demonstrated by different plethysmographic techniques, such as foot volumetry, air plethysmography or strain gauge plethysmography. ${ }^{8,19,21-28}$

With this method we could demonstrate that the ejection fraction (EF) from the lower leg is reduced in patients with chronic venous insufficiency and that it can be improved by external compression. ${ }^{28}$ Inelastic compression material is able to increase $\mathrm{EF}$ from the lower leg and restore normal venous pumping function. The increased EF achieved by inelastic is significantly higher than by elastic material applied with the same pressure. Elastic material never restores the normal function even if applied with high stretch producing a very strong pressure higher than $60 \mathrm{mmHg}$. Therefore not only pressure but also elastic properties of the compression devices play an important role in increasing venous pumping function. In particular the difference between systolic and diastolic pressure during walking (the so called massaging effect) seems to play a deciding role squeezing blood from the leg. The significant correlation between ejection fraction and sub-bandage pressure during standing and walking and between ejection fraction, static stiffness index and walking pressure amplitudes confirm the hemodynamic superiority of inelastic material. ${ }^{29}$

Furthermore inelastic material has been shown to be effective even when applied with a low pressure of $20-30 \mathrm{mmHg}$, (in a range where elastic stocking are unable to increase the ejection fraction) and demonstrated a positive correlation with an increasing application pressure $^{30}$

Finally inelastic materials are claimed to lose effectiveness as they lose pressure overtime. It was proved that this material is able to maintain its effectiveness over time (one week) even despite significant pressure loss. ${ }^{31}$

\section{Edema}

Edema develops because of a complex interaction that involves the permeability of the capillary wall and the hydrostatic and oncotic pressure gradients that exist between the blood vessels and the tissues. ${ }^{32}$ As almost all interstitial fluid is removed by the lymphatic circulation, ${ }^{33}$ edema will form when net capillary filtration exceeds lymphatic drainage capacity. Compression counteracts edema for- mation by increasing the tissue pressure ${ }^{34}$ and lymphatic drainage in the initial stage of lymphatic damage. ${ }^{35}$

Edema is always reduced by compression and the beneficial effect of compression on edema is so clear that only relatively few studies were performed to investigate this effect. Edema is effectively treated by inelastic material applied with very strong pressure and by

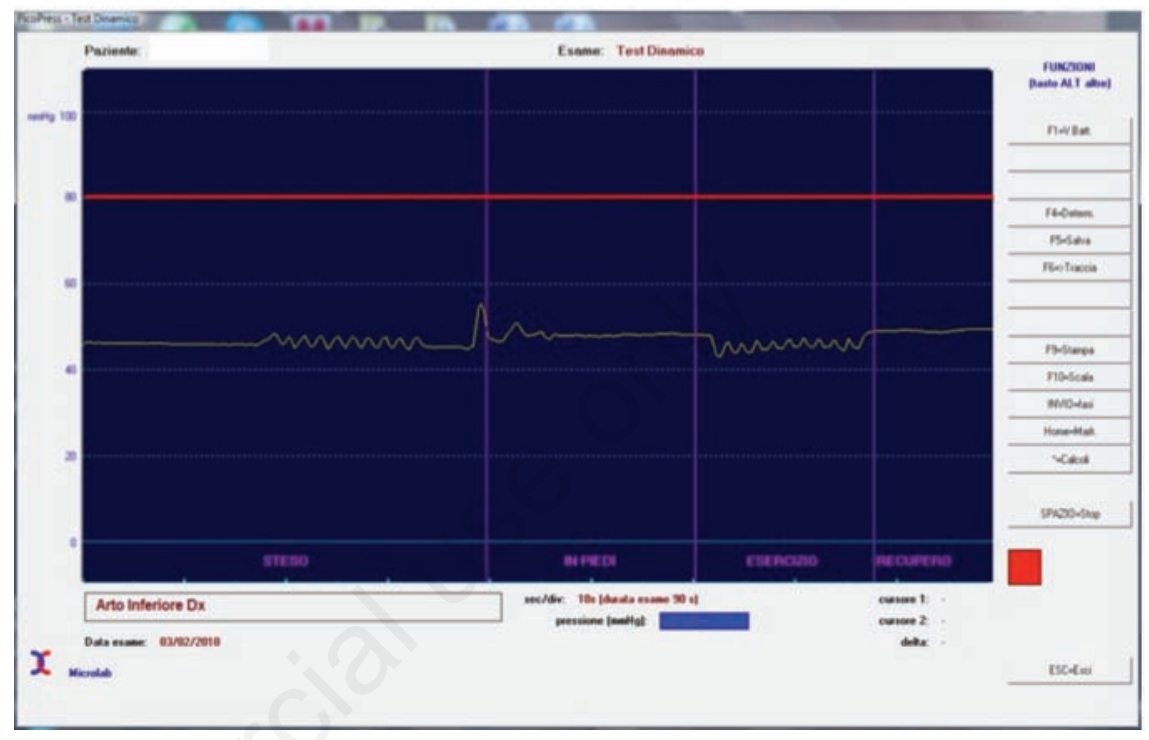

Figure 1. Interface pressure of an elastic compression device applied with $50 \%$ stretch and $50 \%$ overlapping of each layer. The exerted pressure always (during dorsiflexion in the supine position, standing, walking in place) remains well below the intravenous pressure (red line) which would be necessary to compress or occlude the veins.

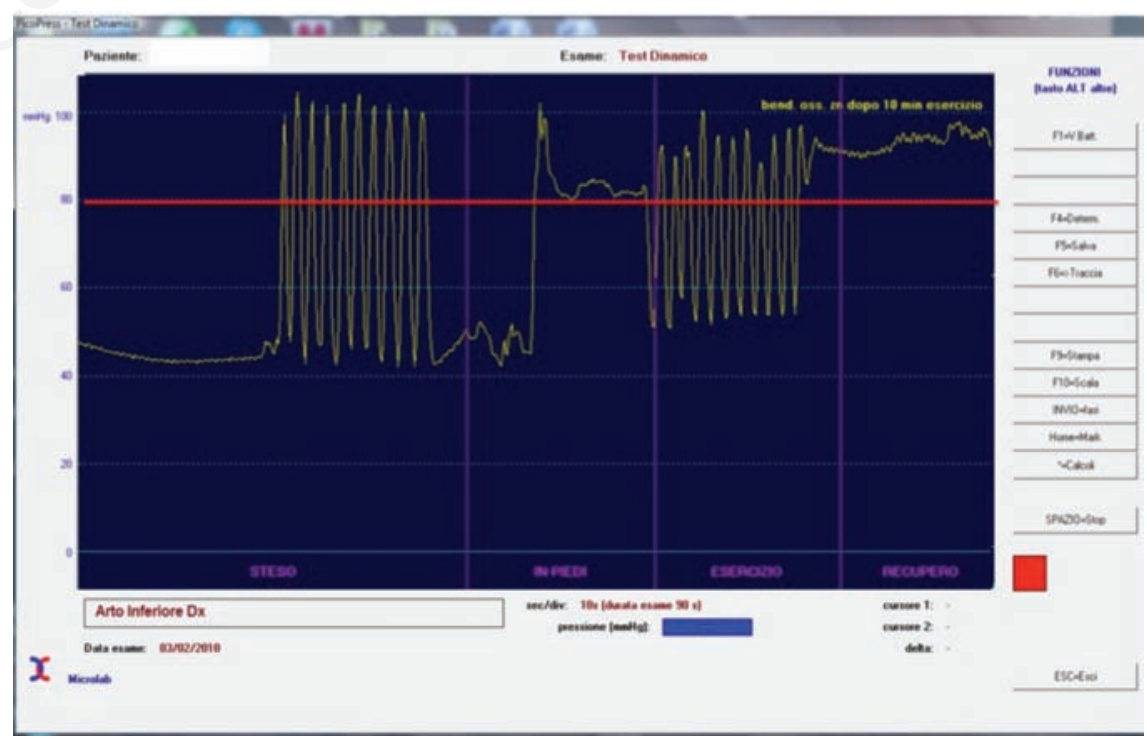

Figure 2. Interface pressure of an inelastic compression device applied with full stretch and $50 \%$ overlapping of each layer. The exerted pressure always (during dorsiflexion in the supine position, standing, walking in place) overcomes the intravenous pressure (red line) narrowing/occluding the veins thus restoring a kind of valve mechanism. 


\section{Conclusions}

There is clear evidence that compression exerted by inelastic materials with high stiffness are able to achieve a very strong pressure starting by low and comfortable pressure at rest. This strong pressure can narrow and even occlude the venous system. This leads to a reduction or even abolition of venous reflux and an improvement or normalization of the venous pumping function. When the supine resting position is resumed the compression pressure is lower and comfortable for the patient, but still effective when ambulation is resumed.

Elastic materials with low stiffness are unable to get strong pressure during standing and ambulation and are much less effective than inelastic with a statistically significant difference. Stiffness plays a deciding role in the hemodynamic effects of compression.

The effect of stiffness in reducing leg edema doesn't seem very relevant so far.

\section{References}

1. Nicolaides A, Christopoulos D. Quantification of venous reflux and outflow obstruction with air-plethysmography. In: Bernstein EF, ed. Vascular diagnosis. St Louis, M0: Mosby; 1993. pp 915-921.

2. Partsch H. Do we still need compression bandages? Haemodynamic effects of compression stockings and bandages. Phlebology 2006;21:132-8.

3. Partsch B, Mayer W, Partsch H. Improvement of ambulatory venous hypertension by narrowing of the femoral vein in congenital absence of venous valves. Phlebology 1992;7:101-4.

4. Ibegbuna V, Delis KT, Nicolaides AN, Aina 0. Effect of elastic compression stockings on venous hemodynamics during walking. J Vasc Surg 2003;37:420-5.

5. Oduncu H, Clark M. Williams RJ. Effect of compression on blood flow in lower limb wounds. Int Wound J 2004;1:107-13.

6. Partsch H, Winiger J, Lun B. Compression stockings reduce occupational leg swelling. Dermatol Surg 2004;30:737-43.

7. Partsch H. Compression therapy in venous leg ulcers. How does it work? J Phlebol 2002;2:129-36.

8. Van Geest AJ, Veraart JC, Nelemans P, Neumann HA. The effect of medical elastic compression stockings with different slope values on oedema. Measurements underneath three different types of stockings. Dermatol Surg 2000;26:244-7.

9. European Committee for Standardization
(CEN). Non-active Medical Devices. Working Group 2 ENV 12718: European Pre-standard 'Medical Compression Hosiery.' CEN TC 205. Brussels: CEN; 2001.

10. Partsch H, Clark M, Bassez S, et al. Measurement of lower leg compression in vivo: recommendations for the performance of measurements of interface pressure and stiffness. Dermatol Surg 2006;32:224-33.

11. Partsch H. The static stiffness index: a simple method to assess the elastic property of compression material in vivo. Dermatol Surg 2005;31:625-30.

12. Partsch $\mathrm{H}$. The use of pressure change on standing as a surrogate measure of the stiffness of a compression bandage. Eur J Vasc Endovasc Surg 2005;30:415-21.

13. Van der Wegen-Franken K, Tank B, Neumann M. Correlation between the static and dynamic stiffness indices of medical elastic compression stockings. Dermatol Surg 2008;34:1477-85.

14. Mosti G, Mattaliano V, Partsch H. Inelastic compression increases venous ejection fraction more than elastic bandages in patients with superficial venous reflux. Phlebology 2008;23:287-94.

15. Partsch B, Partsch H. Calf compression pressure required to achieve venous closure from supine to standing positions. J Vasc Surg 2005;42:734-8.

16. Partsch H, Mosti G, Mosti F. Narrowing of leg veins under compression demonstrated by magnetic resonance imaging (MRI). Int Angiol 2010;29:408-10.

17. Partsch B, Mayer W, Partsch H. Improvement of ambulatory venous hypertension by narrowing of the femoral vein in congenital absence of venous valves. Phlebology 1992;7:101-4.

18. Partsch H. Improving the venous pumping function in chronic venous insufficiency by compression as dependent on pressure and material. Vasa 1984;13:58-64.

19. Partsch H, Menzinger G, Mostbeck A. Inelastic leg compression is more effective to reduce deep venous refluxes than elastic bandages. Dermatol Surg 1999;25:695700 .

20. Mosti G, Partsch H. Duplex scanning to evaluate the effect of compression on venous reflux. Int Angiol 2010;29:416-20.

21. Gjöres JE, Thulesius 0. Compression treatment in venous insufficiency evaluated with foot volumetry. Vasa 1977;6:364-8.

22. Norgren L. Elastic compression stockings: an evaluation with foot volumetry, straingauge plethysmography and photoplethysmography. Acta Chir Scand 1988;154:5057.

23. Partsch H. Do we need firm compression stockings exerting high pressure? Vasa
1984;13:52-7.

24. Christopoulos DG, Nicolaides AN, Szendro G, et al. Air-plethysmography and the effect of elastic compression on venous hemodynamics of the leg. J Vasc Surg 1987; 5:148-59.

25. Spence RK, Cahall E. Inelastic versus elastic leg compression in chronic venous insufficiency: a comparison of limb size and venous hemodynamics. J Vasc Surg 1996;z24:783-7.

26. Ibegbuna V, Delis KT, Nicolaides AN, Aina 0 . Effect of elastic compression stockings on venous hemodynamics during walking. J Vasc Surg 2003;37:420-5.

27. Poelkens F, Thijssen DH, Kersten B, et al. Counteracting venous stasis during acute lower leg immobilization. Acta Physiol (Oxf) 2006;186:111-8.

28. Mosti G, Partsch H. Measuring venous pumping function by strain-gauge plethysmography. Int Angiol 2010;29:421-5.

29. Mosti G, Mattaliano V, Partsch H. Inelastic compression increases venous ejection fraction more than elastic bandages in patients with superficial venous reflux. Phlebology 2008;23:287-94.

30. Mosti G, Partsch H. Is low compression pressure able to improve venous pumping function in patients with venous insufficiency? Phlebology 2010;25:145-50.

31. Mosti G, Partsch H. Inelastic bandages maintain their hemodynamic effectiveness over time despite significant pressure loss. J Vasc Surg 2010;52:925-31.

32. Starling EH. On the absorption of fluids from the connective tissue spaces. J Physiol (London) 1896;19:312.

33. Levick JR, Michel CC. Microvascular fluid exchange and the revised Starling principle. Cardiovasc Res 2010;87:198-210.

34. Murthy G, Ballard RE, Breit GA, et al. Intramuscular pressures beneath elastic and inelastic leggings. Ann Vasc Surg 1994;8:543-8.

35. Partsch H, Stöberl C, Urbanek A, et al. Clinical use of indirect lymphography in different forms of leg edema. Lymphology 1998:21:152-60.

36. Mosti G, Picerni P, Partsch H. Compression stockings with moderate pressure are able to reduce chronic leg oedema. Phlebology 2012;27:289-96.

nction in chronic venous insufficiency by compression as dependent on pressure and material. Vasa 1984;13:58-64.

Partsch H, Menzinger G, Mostbeck A. Inelastic leg compression is more effective to reduce deep venous refluxes than elastic bandages. Dermatol Surg 1999;25:695-700.

Mosti G, Partsch H. Duplex scanning to evaluate the effect of compression on venous reflux. Int Angiol 2010;29:416-20.

Gjöres JE, Thulesius 0. Compression treat- 
ment in venous insufficiency evaluated with foot volumetry. Vasa 1977;6:364-8.

Norgren L. Elastic compression stockings: an evaluation with foot volumetry, straingauge plethysmography and photoplethysmography. Acta Chir Scand 1988;154:5057.

Partsch H. Do we need firm compression stockings exerting high pressure? Vasa 1984;13:52-7.

Christopoulos DG, Nicolaides AN, Szendro G, et al. Air-plethysmography and the effect of elastic compression on venous hemodynamics of the leg. J Vasc Surg 1987;5:14859.

Spence RK, Cahall E. Inelastic versus elastic leg compression in chronic venous insufficiency: a comparison of limb size and venous hemodynamics. J Vasc Surg 1996;24:783-7.

Ibegbuna V, Delis KT, Nicolaides AN, Aina 0.
Effect of elastic compression stockings on venous hemodynamics during walking. $\mathrm{J}$ Vasc Surg 2003;37:420-5.

Poelkens F, Thijssen DH, Kersten B, et al. Counteracting venous stasis during acute lower leg immobilization. Acta Physiol (0xf) 2006;186:111-8.

Mosti G, Partsch H. Measuring venous pumping function by strain-gauge plethysmography. Int Angiol 2010;29:421-5.

Mosti G, Mattaliano V, Partsch H. Inelastic compression increases venous ejection fraction more than elastic bandages in patients with superficial venous reflux. Phlebology 2008;23:287-94.

Mosti G, Partsch H. Is low compression pressure able to improve venous pumping function in patients with venous insufficiency? Phlebology 2010;25:145-50.

Mosti G, Partsch H. Inelastic bandages maintain their hemodynamic effectiveness over time despite significant pressure loss. J Vasc Surg 2010;52:925-31.

Starling EH. On the absorption of fluids from the connective tissue spaces. J Physiol (London) 1896;19:312.

Levick JR, Michel CC. Microvascular fluid exchange and the revised Starling principle. Cardiovasc Res 2010;87:198-210.

Murthy G, Ballard RE, Breit GA, et al. Intramuscular pressures beneath elastic and inelastic leggings. Ann Vasc Surg 1994;8:543-8.

Partsch H, Stöberl C, Urbanek A, et al. Clinical use of indirect lymphography in different forms of leg edema. Lymphology 1998;21: 152-60.

Mosti G, Picerni P, Partsch H. Compression stockings with moderate pressure are able to reduce chronic leg oedema. Phlebology 2012;27:289-96. 